\title{
Preparation of Al-Zn-Mg-Cu alloy semisolid slurry through a water-cooled serpentine pouring channel
}

\author{
*Wen-zhi Zhu', Wei-min Mao', Qing-song Wei ${ }^{1}$, Chen Hui ${ }^{1}$ and Yu-sheng Shi ${ }^{1}$

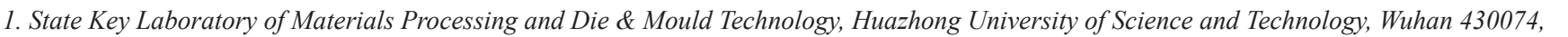 \\ पाणाए

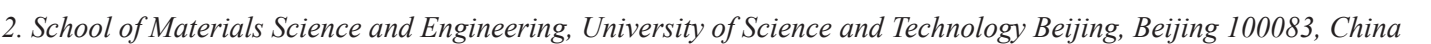

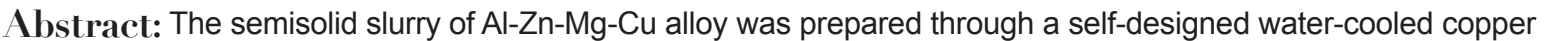
serpentine pouring channel (WSPC) machine. Influences of pouring temperature, the number of turns and the cooling water flow rate on the microstructure of the semisolid $\mathrm{Al}-\mathrm{Zn}-\mathrm{Mg}-\mathrm{Cu}$ alloy slurry were investigated. The results show that the semisolid Al-Zn-Mg-Cu alloy slurry with satisfactory quality can be generated by the WSPC when the pouring temperature is in the range between $680^{\circ} \mathrm{C}$ and $700^{\circ} \mathrm{C}$. At a given pouring temperature, the average grain size of primary $\alpha-A l$ decreases and the shape factor increases with the increase of the number of turns. When the cooling water flow rate is $450 \mathrm{~L} \cdot \mathrm{h}$, the obtained semisolid slurry is optimal. During the preparation of the semisolid Al-Zn-Mg-Cu alloy slurry with low superheat pouring, the alloy melt has mixed inhibition and convection flow characteristics by "self-stirring". When the alloy melt flows through the serpentine channel, the chilling effect of the inner wall of the channel, the convection and mixed inhibition of the alloy melt

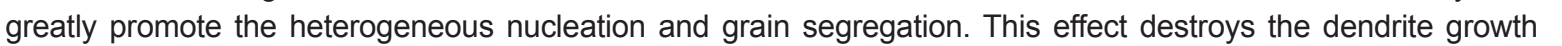
mode under traditional solidification conditions, and the primary nuclei gradually evolve into spherical or near-
\end{abstract}

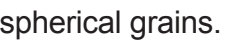

Key words: Al-Zn-Mg-Cu Alloy; semisolid slurry; water-cooled serpentine channel; primary a-Al

CLC numbers: TG146.21～Document code:AＡrticle ID: 1672-6421(2019)01-031-09

emisolid metal (SSM) forming has been a new
booming casting process since 1971 when it was
initially found by Flemings ${ }^{[1]}$. The typical characteristic
of SSM slurry is that copious amounts of globular grains
uniformly suspend within the "mother" alloy melt ${ }^{[2]}$.
Therefore, the preparation of semisolid slurry is the key
for SSM forming. It is considered that the forming of non-
dendrites or globe grains was mainly caused by breaking
up of primary dendrites. In order to obtain the desired
semisolid slurry, some techniques have been investigated,
such as mechanical stirring ${ }^{[3-4]}$ and electromagnetic
stirring ${ }^{[5-6]}$, both of which are accompanied with indirect
ultrasonic vibration ${ }^{[7]}$. Compared with mechanical
stirring, electromagnetic stirring is highly efficient and

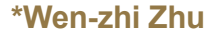

Male, born in 1984, Ph.D., Lecturer. His research interests mainly focus on

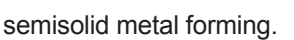

E-mail: 3012605024@qq.com clean, and is widely applied in industrial production. In the processes of near liquidus casting ${ }^{[8-9]}$, low superheat semisolid forming ${ }^{[10]}$ or MSMT (melt spreading and mixing technology) ${ }^{[11]}$, copious non-dendritic or globular grains nucleated from the liquid phase because of a rather great super-cooling degree. Furthermore, in other SSM forming processes such as Angular Oscillation ${ }^{[12]}$ and cooling slope process ${ }^{[13]}$, the aim is to produce forced convection in the super-cooling melt to make a high density of non-dendrite or globular grains nucleate throughout the melt in the early stages of solidification, and finally, a cast microstructure that predominantly consists of globular grains could be achieved $^{[14]}$.

The serpentine channel preparation of semisolid metal slurry technology was a recently proposed method for preparing slurry without external force. The semisolid A356 aluminum alloy slurry with satisfactory quality can be prepared by this method ${ }^{[15-16]}$, but to realize the industrial application, further research is needed for 
the selection of proper alloys. The 7075 aluminum alloy is a high strength deformed aluminum alloy of the Al-Zn-Mg$\mathrm{Cu}$ system, which has been applied in various fields such as aircraft and automobile manufacturing. However, hot cracks and shrinkage holes easily occur in the solidification of 7075 aluminum alloy castings. Therefore, a new type of Al$5.44 \mathrm{Zn}-3.68 \mathrm{Mg}-2.10 \mathrm{Cu}$ alloy was used, which can eliminate hot cracks ${ }^{[17]}$. In the previous research, the semisolid 7075 aluminum alloy slurry has been prepared by graphite serpentine channel, which is not conducive to continuous pumping due to the limited chilling capacity of graphite ${ }^{[18-19]}$. In this study, the semisolid Al-5.44Zn-3.68Mg-2.10Cu alloy slurry was prepared by the water-cooled copper serpentine pouring channel (WSPC) which has two advantages. One is the chilling capacity of copper is stronger than graphite. When the alloy melt flows through the channel, it is easier to obtain heterogeneous nucleation. The number of crystal nuclei is greater and the size of the grain in the slurry is smaller. The other is that when the slurry is prepared by WSPC, the continuous cooling water is cooled to the channel, which is conducive to continuous pumping. The processing parameters on the microstructure of semisolid A1-5.44Zn$3.68 \mathrm{Mg}-2.10 \mathrm{Cu}$ alloy slurry were investigated. Furthermore, the formation mechanism of non-dendritic microstructures by WSPC was discussed.

\section{Experimental procedure}

The experimental material used for slurry preparation was an Al$5.44 \mathrm{Zn}-3.68 \mathrm{Mg}-2.10 \mathrm{Cu}$ alloy with the chemical composition as shown in Table 1. The solidus and liquidus temperatures of Al5.44Zn-3.68Mg-2.10Cu alloy are $474{ }^{\circ} \mathrm{C}$ and $630{ }^{\circ} \mathrm{C}$ tested by differential scanning calorimetric (DSC) method. It is obvious that the solid-liquid phase range of the Al-5.44Zn-3.68Mg$2.10 \mathrm{Cu}$ alloy is $156^{\circ} \mathrm{C}$, which is available for semisolid forming.

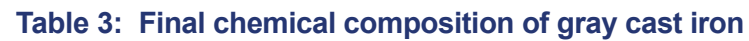

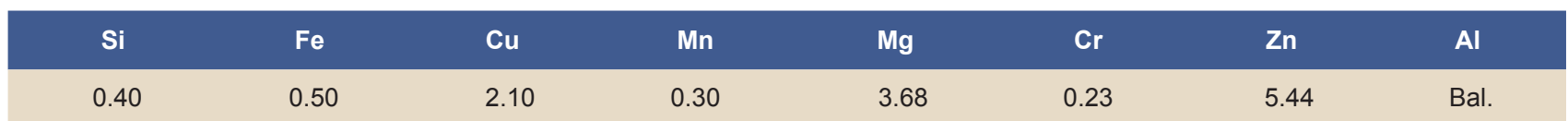

The schematic of WSPC apparatus and the slurry preparation process is shown in Fig. 1. The WSPC is made of copper and it consists of two symmetrical blocks locked together by screw bolts and nuts. The collective crucible is made of stainless steel. A Ni-Cr/Ni-Si thermocouple was used to measure the temperatures of the melt and the slurry.

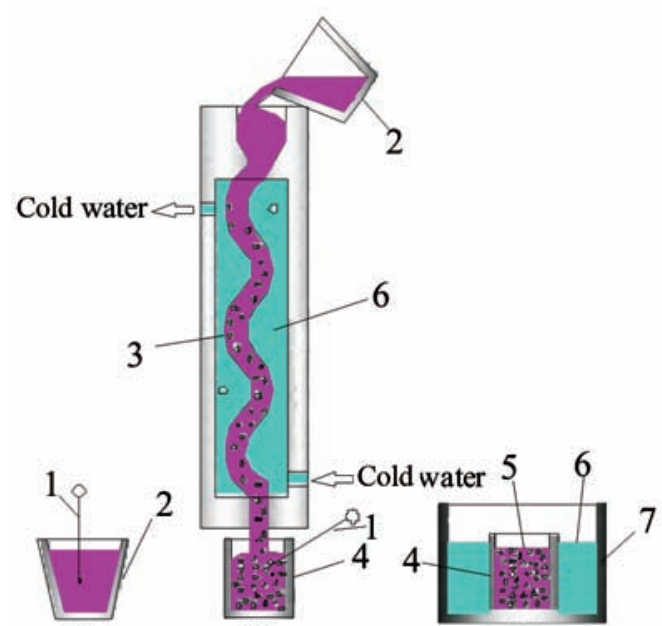

(a) Melting stage $\quad$ (b) Pouring stage

(c) Water quenching stage

1 - K-type thermocouple; 2 - Melting crucible; 3 - WSPC;

4 - Collective crucible; 5 - Slurry; 6 - Cold water; 7 - Pool

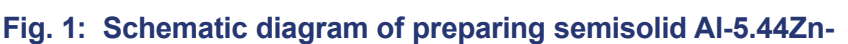

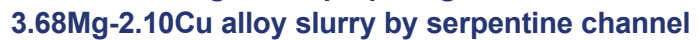

The alloy was melted in a crucible resistance furnace at 750 ${ }^{\circ} \mathrm{C}$, and held for $10 \mathrm{~min}$. The melt was cooled to the chosen pouring temperature and cast into a stainless steel crucible via serpentine channel. Then the slurry was rapidly quenched in cold water. The processing parameters of preparing the semisolid slurry are shown in Table 2 . The resulting solidified slurry was sectioned horizontally from the middle. The thickness of the wafer was about $10 \mathrm{~mm}$. Then the fan-shaped samples were cut from the wafers, as shown in Fig. 2. The center zone of samples was considered during microstructure observation. In order to compare and analyze the microstructure difference between the semi-solid slurry and the conventional solidification, the conventional casting was also carried out under the same technological conditions. The microstructures of the samples were analyzed by SEM after being polished and etched in Keller's reagent for $25 \mathrm{~s}$. The diameter of primary $\alpha$-Al grains was calculated as: $\square=2(\square / \pi)^{1 / 2}$ (where $\square$ represents the area of a grain), and the shape factor of primary $\alpha-\mathrm{Al}$ grains was calculated as: $\square=4 \pi \square \square 2$ (where $\square$ represents the perimeter of a grain).

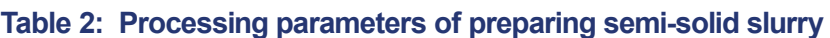

\begin{tabular}{ccc}
\hline $740,720,700,680$ & $\square$ & $\begin{array}{c}\text { flow rate (L.h } \\
720\end{array}$ \\
720 & 3,4 & 450 \\
\hline & $\square$ & $0,450,900$
\end{tabular}

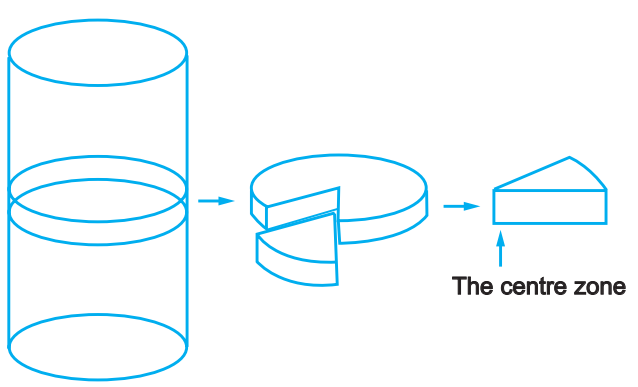
from solidified slurry 


\section{Results}

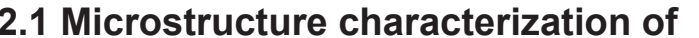

\section{conventional solidification and semisolid}

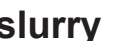

Figure 3 shows the microstructures of A1-5.44Zn-3.68Mg$2.10 \mathrm{Cu}$ alloy billet prepared by conventional casting at $700{ }^{\circ} \mathrm{C}$ and quenched at $630^{\circ} \mathrm{C}$ without using serpentine channel. As can be seen in Fig. 3(b), the black phase is primary $\alpha-\mathrm{Al}$ precipitated preferentially during solidification and the white matrix is the $\alpha-\mathrm{Al}+\eta\left(\mathrm{MgZn}_{2}\right)$ eutectic phase precipitated along the grain boundary in the later solidification stage. Most of the primary $\alpha-\mathrm{Al}$ grains are dendrites with coarse branches, and some typical dendrites with length of more than $200 \mu \mathrm{m}$ are observed. A small proportion of equiaxed grains in the middle of the sample are found because of the temperature and constituent fluctuation during the pouring process. Figure 4 shows the microstructures of the semisolid slurry prepared at $700{ }^{\circ} \mathrm{C}$ by 4-turn WSPC with a $450 \mathrm{~L} \cdot \mathrm{h}^{-1}$ cooling water flow rate. It is clear that the solidification microstructures consist of non-dendrites primary $\alpha$-Al grains which disperse uniformly in the matrix and eutectics at intergranular boundaries. The grain diameter and the shape factor of primary $\alpha$-Al grains are $38 \mu \mathrm{m}$ and 0.80 , respectively. It is concluded that the size and morphology of primary $\alpha-\mathrm{Al}$ grains are significantly influenced by pouring method.
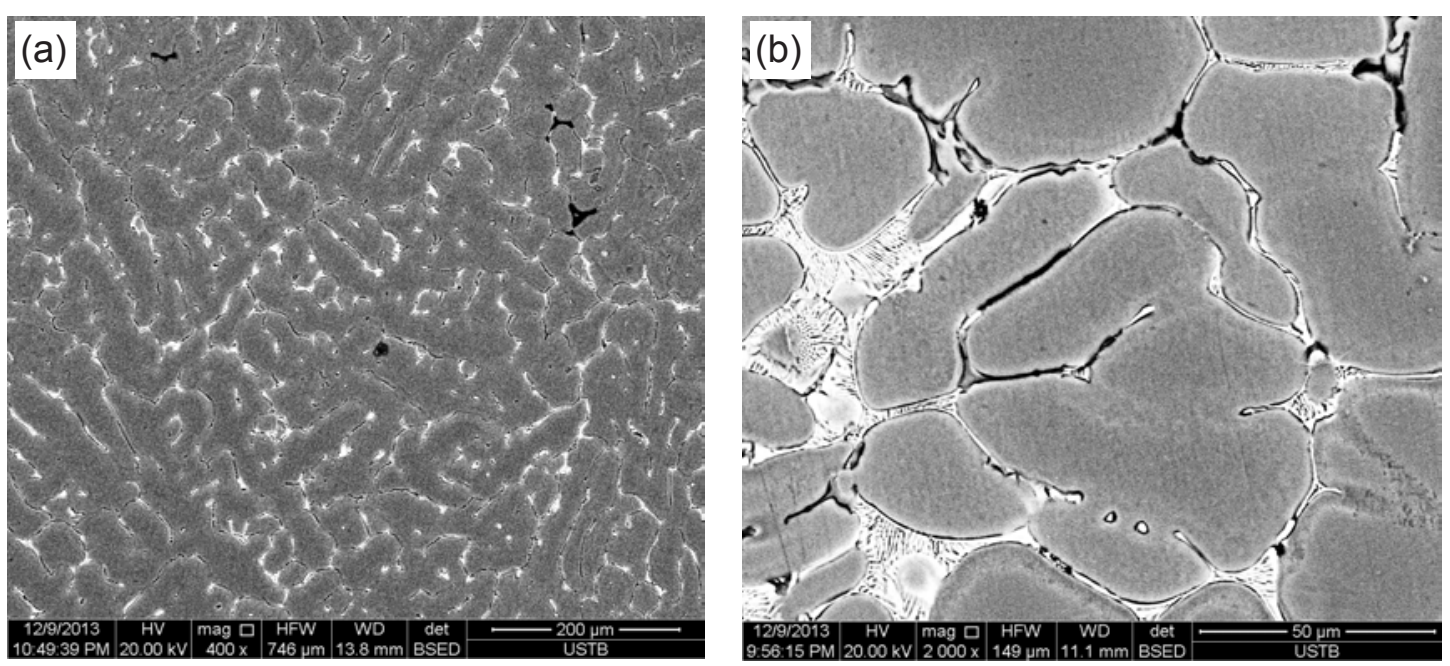

Fig. 3: Typical dendrite microstructures of conventional solidification
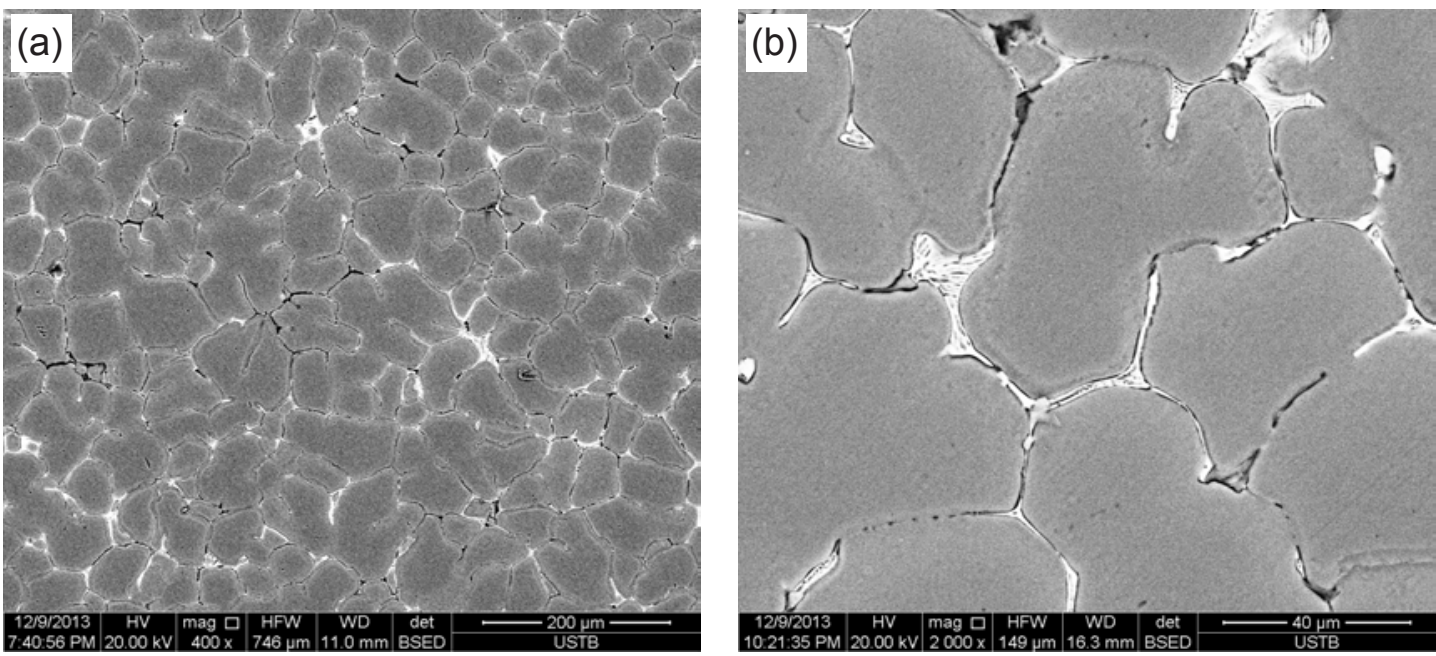

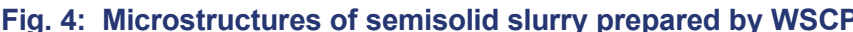

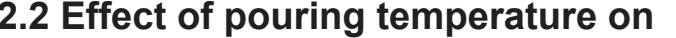

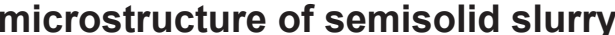

Figure 5 shows the microstructure of semi-solid slurry prepared by 4 turns WSCP with a $450 \mathrm{~L} \cdot \mathrm{h}^{-1}$ cooling water flow rate at the temperatures of $740{ }^{\circ} \mathrm{C}, 720^{\circ} \mathrm{C}, 700{ }^{\circ} \mathrm{C}$ and $680^{\circ} \mathrm{C}$, respectively. When the pouring temperature is $740{ }^{\circ} \mathrm{C}$, the primary $\alpha$-Al grains mostly are rosette-like or dendrite, and the others are irregular or near-spherical and some are still stuck together, as shown in Fig. 5(a). The average grain diameter is $43 \mu \mathrm{m}$ and the shape factor is 0.74 . A similar microstructure can be seen and some grains still contacted each other at $720{ }^{\circ} \mathrm{C}$, but the primary $\alpha-\mathrm{Al}$ grains are gradually refined, as shown in Fig. $5(\mathrm{~b})$. The average grain diameter is $41 \mu \mathrm{m}$ and the shape factor is 0.79 . When a lower pouring temperature such as $700{ }^{\circ} \mathrm{C}$ is adopted, 
most contacted grains separate and the primary $\alpha$-Al grains become more spherical, as shown in Fig. 5(c). The average grain diameter is $38 \mu \mathrm{m}$ and the shape factor is 0.80 . Figure $5(\mathrm{~d})$ shows the alloy melt poured at $680^{\circ} \mathrm{C}$, almost all of the primary $\alpha$-Al grains are near-spherical or spherical, as well as a small number of rosettes. The average grain diameter is $36 \mu \mathrm{m}$, and the shape factor is 0.83 . Figure 6 shows the relationship between pouring temperature and the average grain diameter and shape factor of primary $\alpha-\mathrm{Al}$ in the semi-solid slurry, respectively. It is obvious that the average grain diameter decreased and the shape factor increased with the pouring temperature decreasing.
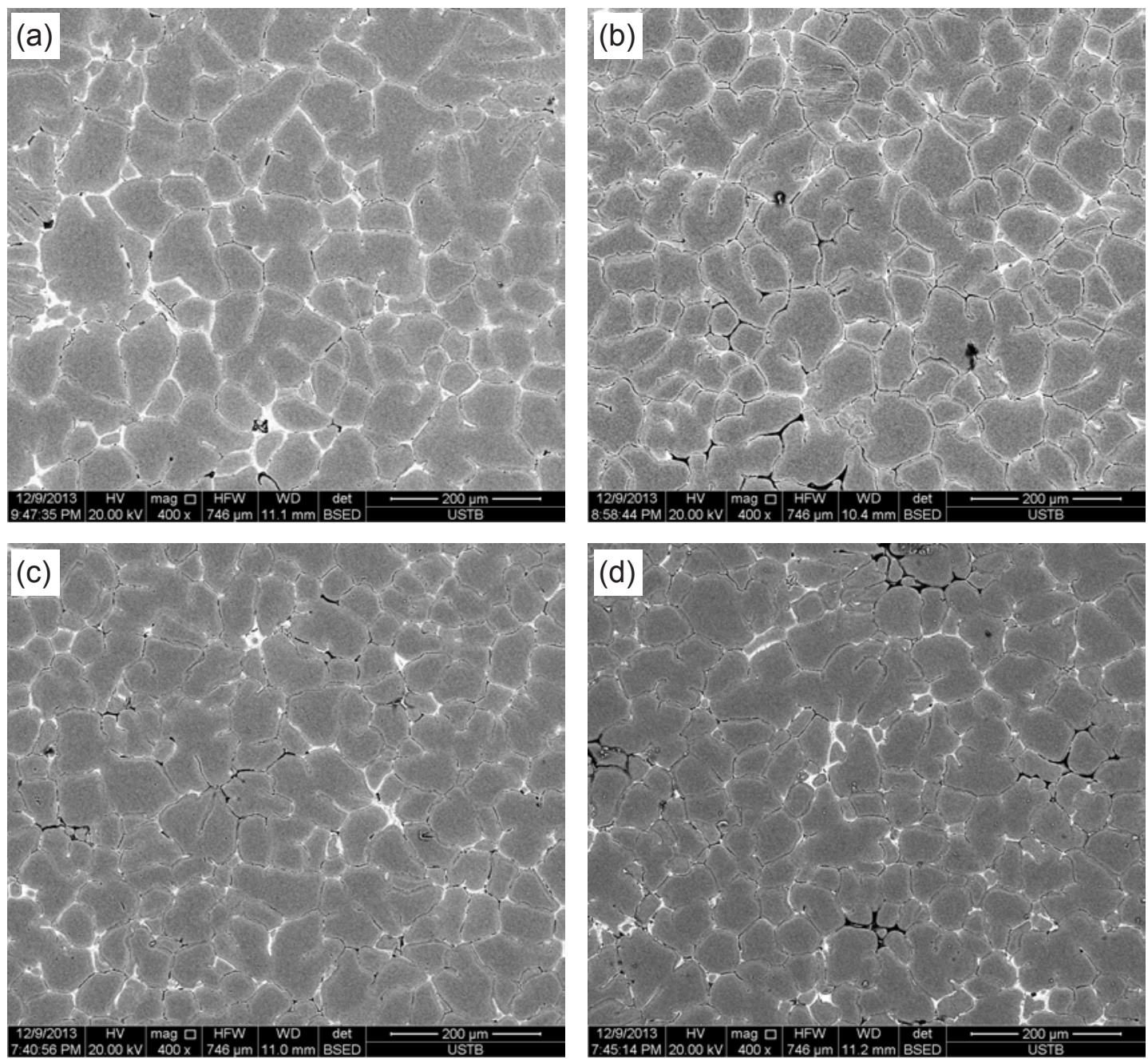

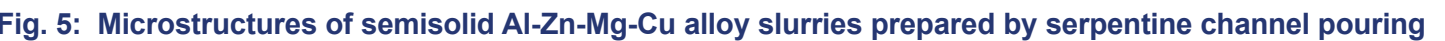

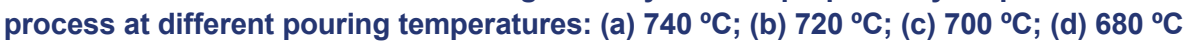

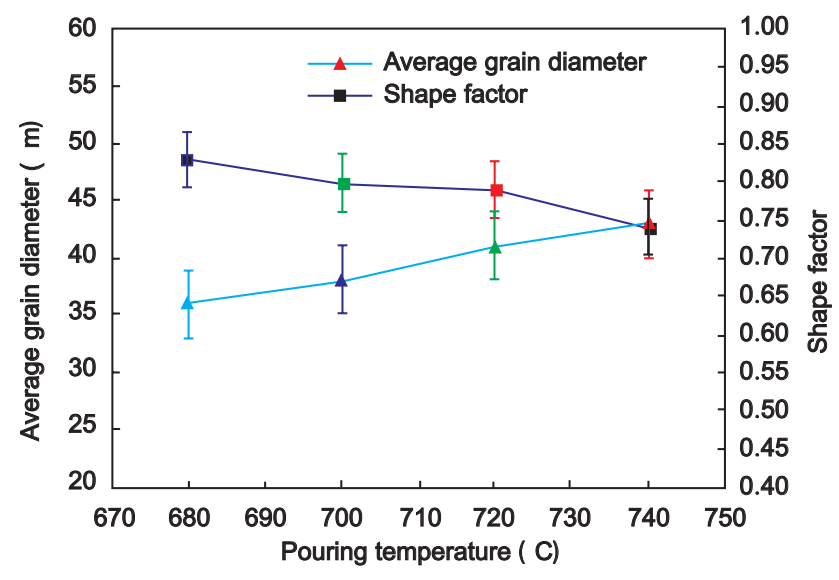

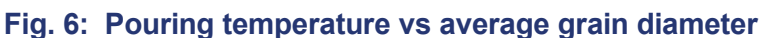

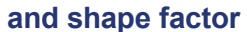

During the preparation of semi-solid slurry, the heat exchange between the slurry and the inner wall of WSPC, the chilling effect of the inner wall and the nucleation ratio of the slurry vary with different pouring temperatures. When the pouring temperature is high, the temperature of the inner wall will be high because of more sufficient heat exchange. The primary $\alpha$-Al grains may be remelted under the superheat of WSPC. If the pouring temperature is low, the temperature of the slurry in the serpentine channel will rapidly drop to below the liquidus temperature. Meanwhile, the inner wall of the channel absorbs less heat. The subsequent alloy melt flowing through the channel more easily reaches heterogeneous nucleation. It can be concluded that the better spheroidization of dendrites $\alpha$-Al can be obtained with a relatively lower pouring temperature by using WSCP. However, the pouring temperature should not be too low; otherwise, the slurry in serpentine channel may plug 
up the channel. So the best pouring temperature range in this experiment is between $680{ }^{\circ} \mathrm{C}$ and $700{ }^{\circ} \mathrm{C}$.

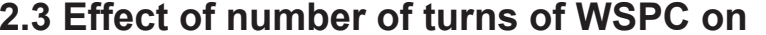

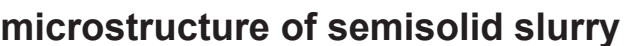

Figure 7 shows the microstructure of semi-solid slurry prepared by 3 and 4 turns copper serpentine channel with the $450 \mathrm{~L} \cdot \mathrm{h}^{-1}$ cooling water flow rate at $680{ }^{\circ} \mathrm{C}$. When the serpentine channel with 3 turns was applied, the morphology of primary $\alpha$-Al grains is mainly rosette-like or near-spherical, as shown in Fig. 7(a). The average grain diameter is $40 \mu \mathrm{m}$ and the shape factor is 0.79 . As the applied serpentine channel turns increase from 3 to 4, the primary $\alpha$-Al grains are gradually refined, and their morphologies are mainly near-spherical with some being rosette-like, as shown in Fig. 7(b). The average grain diameter is $36 \mu \mathrm{m}$, and the shape factor is 0.83 . It should be noted that when the serpentine channel with 4 turns was applied, the average grain diameter decreased and the shape factor increased.
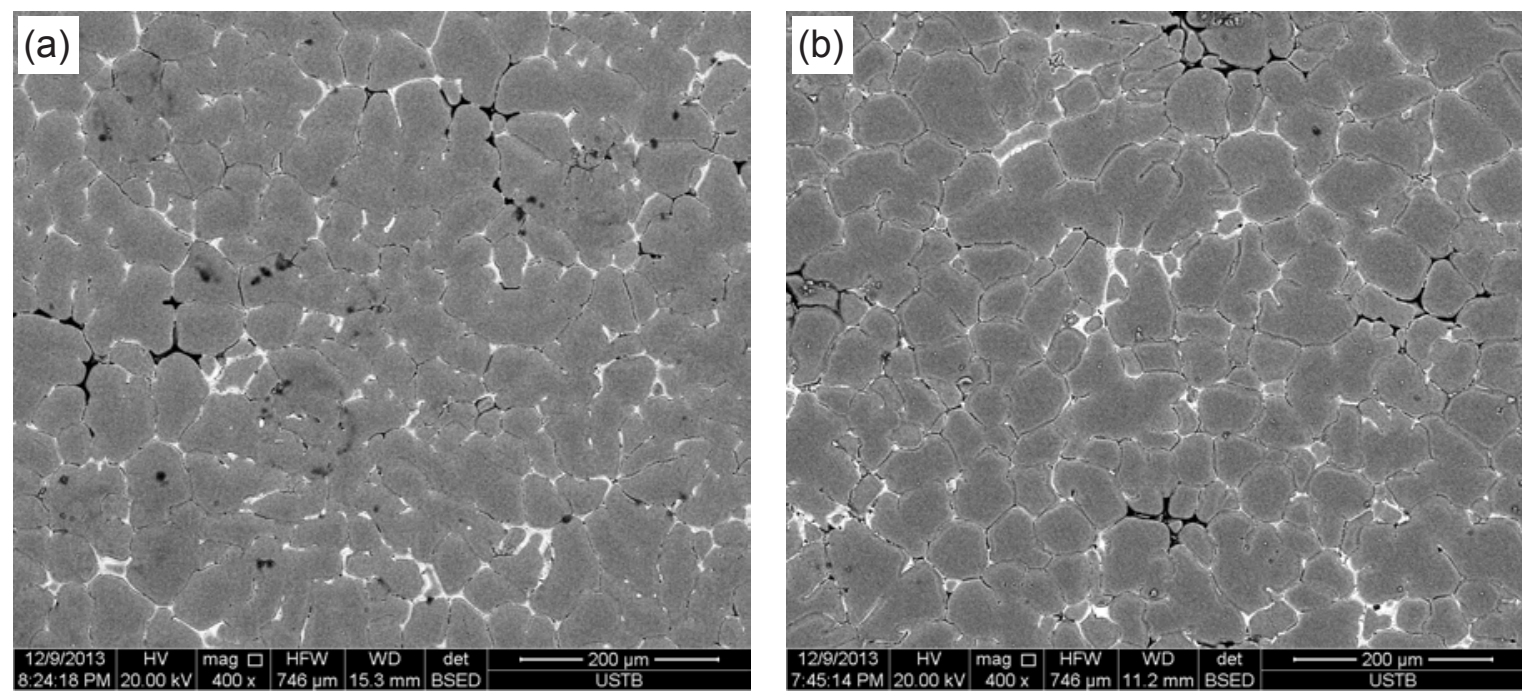

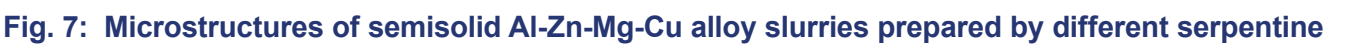

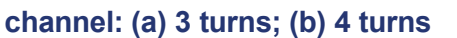

The results show that the morphology of primary $\alpha-\mathrm{Al}$ in semi-solid slurry changes from rosette-like or dendritic to nearspherical or spherical when the number of turns change from 3 to 4 . The number of turns is a factor that determines the thermal conductivity of the channel. In designing the serpentine channel, when the greater number of turns is designed, the serpentine channel has a longer length. In this work, the length of 3-turn and 4-turn serpentine channel is $395 \mathrm{~mm}$ and $427 \mathrm{~mm}$, respectively. With the same pouring temperature and cooling water flow rate, the chilling time of 4-turn serpentine channel is longer than 3-turn serpentine channel due to its longer length, which will increase the cooling range, enhance the cooling effect and prove beneficial for heterogeneous nucleation and heat diffusion of slurry. Meanwhile, the self-stirring effect of the slurry was enhanced and more primary $\alpha-\mathrm{Al}$ nuclei will be generated and remained. Moreover, the intensity of the "selfstirring" will be strengthened with the turns number increasing. Therefore, the better spheroidization of dendritic $\alpha$-Al can be obtained with 4-turn serpentine channel compared to the one with 3-turn.

\subsection{Effect of cooling water flow rate on}

Figure 8 shows the microstructure of semi-solid slurry prepared by 4-turn copper serpentine channel with $0 \mathrm{~L} \cdot \mathrm{h}^{-1}, 450 \mathrm{~L} \cdot \mathrm{h}^{-1}$ and $900 \mathrm{~L} \cdot \mathrm{h}^{-1}$ cooling water flow rate at the temperature of $740{ }^{\circ} \mathrm{C}$, respectively. Figure 9 shows the relationship between cooling water flow rate and grain diameter and the shape factor of primary $\alpha$-Al grains in a semi-solid slurry. When the cooling water flow rate is $0 \mathrm{~L} \cdot h^{-1}$, the morphology of primary $\alpha$-Al grains are mostly irregular or near-spherical, and the others are rosettelike or dendrites, as shown in Fig. 8(a). The average grain diameter is $45 \mu \mathrm{m}$ and the shape factor is 0.72 . When the applied cooling water flow rate increases from $0 \mathrm{~L} \cdot h^{-1}$ to $450 \mathrm{~L} \cdot \mathrm{h}^{-1}$, the primary $\alpha$-Al grains are gradually refined with more roundness, and their morphologies are near-spherical, as shown in Fig. 8(b). The average grain diameter is $43 \mu \mathrm{m}$ and the shape factor is 0.74 . When the applied cooling water flow rate is further increased to $900 \mathrm{~L} \cdot \mathrm{h}^{-1}$, the number of primary $\alpha$-Al rosette-like grains in the slurry structure increases, and the grain size is inhomogeneous, as shown in Fig. 8(c). The average grain diameter is $46 \mu \mathrm{m}$ and the shape factor is 0.70 .

Results show that with the increase of the cooling water flow rate, the morphology of primary $\alpha-\mathrm{Al}$ in semi-solid slurry becomes refined with more roundness, and then becomes coarser and inhomogeneous with further increasing of the water flow rate. As can be seen in Fig. 8, the average grain diameter firstly decreases with the cooling water flow rate increasing and then increases. The shape factor shows an opposite changing trend, firstly increasing with the cooling water flow rate increasing and then decreasing. With the same pouring temperature and the same number of turns, the cooling water flow rate determines the cooling capacity of the serpentine channel. Compared with the cooling water flow rate of $0 \mathrm{~L} \cdot \mathrm{h}^{-1}$, the chilling effect of 

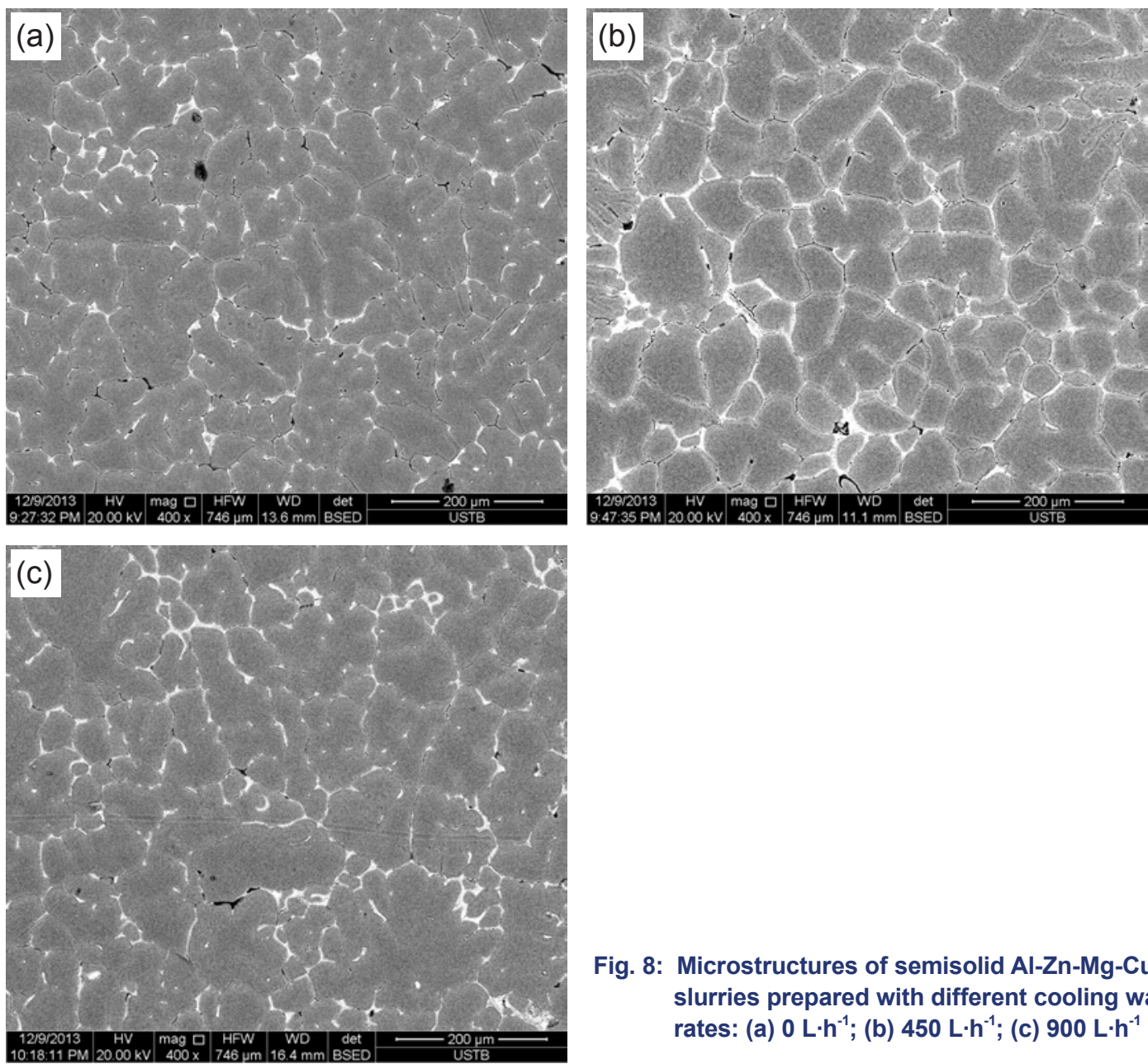

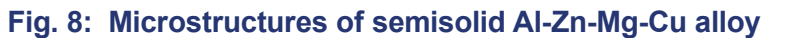
slurries prepared with different cooling water flow rates: (a) $0 \mathrm{~L} \cdot h$; ; (b) $450 \mathrm{~L} \cdot \mathrm{h}^{\text {; }}$; (c) $900 \mathrm{~L} \cdot \mathrm{h}$

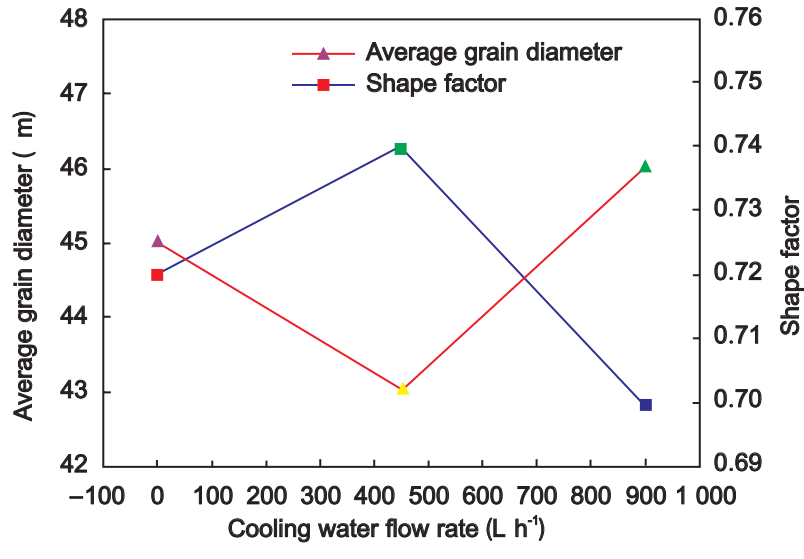

Fig. 9: Cooling water flow rate vs average grain diameter

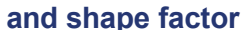

the melt is greater and the nucleation work of primary $\alpha$-Al is reduced with $450 \mathrm{~L} \cdot \mathrm{h}^{-1}$ cooling water flow rate, which is more conducive to the nucleation of the alloy melt. When the cooling water flow rate is further increased to $900 \mathrm{~L} \cdot \mathrm{h}^{-1}$, the cooling capacity of the serpentine channel continues to increase and heterogeneous nucleation becomes easier in the inner wall of the serpentine channel. As the intensity of cooling is too high, the primary $\alpha-\mathrm{Al}$ grains in the inner wall of the serpentine channel nucleated in a short period of time and rapidly grew in the form of dendrites, and the primary $\alpha$-Al crystal nuclei are difficult to be fully separated by scour of the subsequent alloy melt. The free primary $\alpha$-Al crystals washed away are relatively coarse dendrites, which evolve into rose-shaped and near-spherical grains during subsequent growth. Therefore, the optimal spheroidization of dendritic $\alpha$-Al can be obtained with $450 \mathrm{~L} \cdot \mathrm{h}^{-1}$ cooling water flow rate.

\section{Discussion}

\subsection{Heterogeneous nucleation of primary $\alpha-A l$}

\section{(I)}

When the alloy melt flows through the serpentine channel, the main direction of heat radiation is perpendicular to the inner wall of a serpentine channel. Figure 10 shows the temperature distribution of the melt in the cross-section of the serpentine channel, which includes the semi-solid state melt and liquid state melt. The semi-solid state melt is divided into two parts: one part closely adjoining the inner wall has a large degree of super-cooling, forming the boundary layer; and the other part between the boundary layer and the liquid phase area is the transition layer. The alloy melt in the boundary layer is the main source of the primary $\alpha$-Al nuclei.

The main mechanism of crystal nucleation of the alloy melt on the inner concave surfaces of the serpentine channel was heterogeneous nucleation, whose nucleation ratio depended 


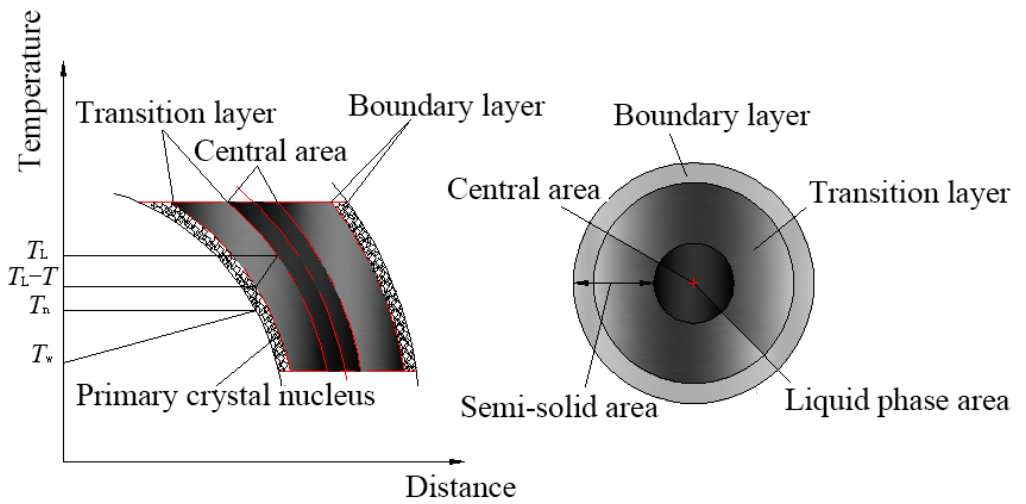

$T_{\mathrm{L}}$ - Liquidus temperature; $T$ (

$T$ (

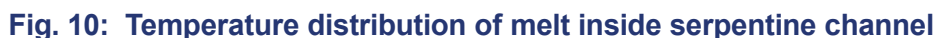

on the critical energy of nucleation and the activation energy of diffusion of the atom in the liquid phase. During the pouring process, the alloy melt flowed down along the inner concave surfaces by the action of gravity, whose velocity varied with time and displacements were different in different points, both of which can lead to the occurrence of shearing forces. What's more, the magnitudes and directions of shearing forces were varying with the positions of the alloy melt, in a word, all of which could be seen as the serpentine channel's action of self-stirring. Further, turbulence caused by the action of self-stirring of the alloy melt was beneficial for crystal nucleation. At the same time, energy fluctuation decreased the critical energy of nucleation and therefore increased the nucleation ratio. The supercooling of the alloy melt on the surfaces of the serpentine channel promoted the crystal nucleation which was tightly stuck to the inner surfaces of the serpentine channel. In addition, the nucleation substrate was concave surface that was better for crystal nucleation than other surfaces such as horizontal surfaces or convex surfaces. Besides, the density of the alloy melt near the inner concave surfaces was different from that near the central area in the serpentine channel, which caused the fast convection amid the alloy melt. The fast convection also caused the temperature of the alloy melt to be relatively uniform and to decrease.

In addition, the mixed inhibition and convection of the alloy melt accelerates the diffusion rate of the solute, which increases the chance of atoms being trapped by critical embryos and increasing the nucleation rate. A part of the formed crystal nuclei falls off into the residual alloy melt and flows downward, and then becomes free crystals. If the nucleus is free to the transition layer, this part of the primary $\alpha$-Al nuclei can survive and continue to grow into grains or become the core of other nuclei proliferations due to the temperature being lower than the liquidus temperature. If the nucleus is free to the central state of the channel, this part of the primary $\alpha$-Al nuclei will be remelted and flow downward with the alloy melt due to the temperature being higher than the liquidus temperature. Another part of the primary $\alpha$-Al nuclei will remain on the inner wall of the turn and continue to grow, forming a solidified shell that remains inside the turn.

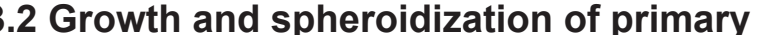

\section{$\alpha-A l$ in WSPC}

The temperature gradient of the solid-liquid frontier, the concentration gradient of solutes and the intensity and direction of heat diffusion of the alloy melt in the serpentine channel decided the future microstructures of primary crystal nuclei. During the WSPC process, the fast convection in the alloy melt caused the rapid mixing of inner heat and different parts of the alloy melt, which made the component and the temperature field of the melt on the whole relatively even and the temperature and concentration gradient decrease. Along with the motion in the convection of the melt, the fast self-rotating of these crystal nuclei put themselves in a relatively even growing circumstance and made them continuously change their positions when they moved down, which weakened the requirements of dendrites emerging by a large scale. Under this condition, the crystal nuclei would grow up evenly in all directions and finally turn into spherical grains or near spherical grains.

Figure 11 shows the evolution of primary $\alpha$-Al and spheroidization inside the serpentine channel. When the alloy melt just enters the serpentine channel, the free crystal is spherical and the size is very small due to the chilling of the inner wall of the channel. In the boundary layer close to the inner wall of the channel, the degree of stirring and mixing during the flushing action is weak and the solute does not migrate much due to the transition layer near the upper turn of the channel having a lower degree of undercooling. These chilled free crystals gradually grow up into isometric free crystals, as shown in Fig. 11(b).

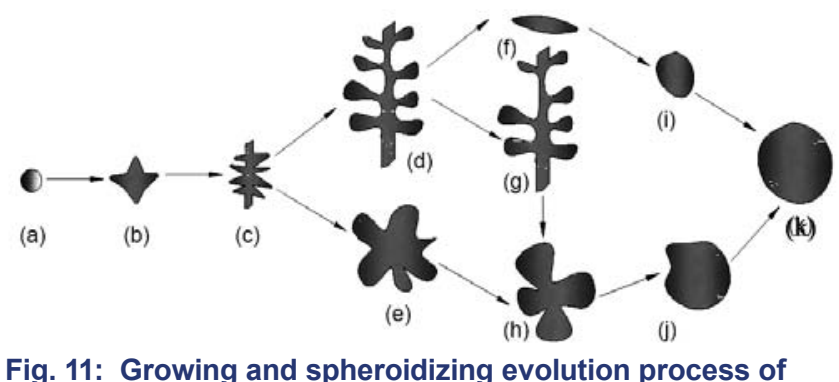

primary $\alpha-A l$ grain inside serpentine channel 
When the alloy melt flows down the channel, the supercooling degree of the transition layer becomes greater and the area also becomes wider gradually. The scouring action of the inner wall of the channel by the alloy melt becomes intense. The equiaxed free crystals transfer to the transition layer and grow into smaller dendrites, as shown in Fig. 11(c). Meanwhile, most of the small dendrites near the boundary layer continue to grow, as shown in Fig. 11(d). The dendritic arm ends of the small dendrite near the central area begin to melt and the root becomes thick, as shown in Fig. 11(e). When the alloy melt continues to flow down to the middle and bottom of the serpentine channel, the number of primary $\alpha-\mathrm{Al}$ crystal grains increases substantially due to the super-cooling degree of the transition layer becoming larger, and the effect of stirring and washing becomes more intense. At this time, the secondary dendrite arms of the grown dendrites are necking and melting, as shown in Fig. 11(f) and (g). When the primary $\alpha$-Al grains flow downward along with the alloy melt, mechanical forces such as collision and friction occur between the grains, and the crystal grains are constantly scoured by the alloy melt. These external forces may inhibit the growth of dendritic arms, so it is beneficial to the aging and the spherical growth of the crystal grains. In addition, the heat flow in the central area continuously passes through the transition layer, so that the temperature of the alloy melt in the transition layer fluctuates greatly, which also helps the secondary dendrite arms fuse from the root.

When the melt flows to the lower part of the serpentine channel, the number of primary $\alpha$-Al grains in the transition layer is large, including the formed primary $\alpha$-Al grains, the growing primary $\alpha-\mathrm{Al}$ grains, the dendrite fragments, and the matured rosette grains. At this time, the ends of different primary $\alpha-\mathrm{Al}$ grains are very close to or in contact with each other and the concentration field and temperature field overlap each other. The growth of the ends is inhibited and has no direction. As a result, fragments of these dendrites and the ripened rosettes will turn into relatively dense rosettes, as shown in Fig. 11(h), (i) and (j). However, the secondary dendrite arms of the newly generated primary $\alpha$-Al grains are not developed and the trunks between the grains are not very close to each other. The interference between density field and temperature field of the trunk are very weak, so these grains continue to grow into dendrites. These secondary dendrite arms separated by necking and some of the main trunks have begun to roughen. When the alloy melt is in the final turn, the primary $\alpha-\mathrm{Al}$ grains are further matured and grow into the nearly spherical grains, as shown in Fig. 11(k)

Figure 12 shows the microstructures of the solidified shell in places "A" and "B". The rosette grains in Fig. 12(b) were less than Fig. 12(a), but the near spherical grains were relatively more, which was a piece of further evidence that the microstructure formation mechanism of the semi-solid slurry. The alloy melt self-stirring action in the channel could prevent the primary crystal nuclei from growing into dendrites; on the contrary, the crystal nuclei would be inclined to turn into spherical or near spherical grains by the comprehensive functions of being washing down and convection.
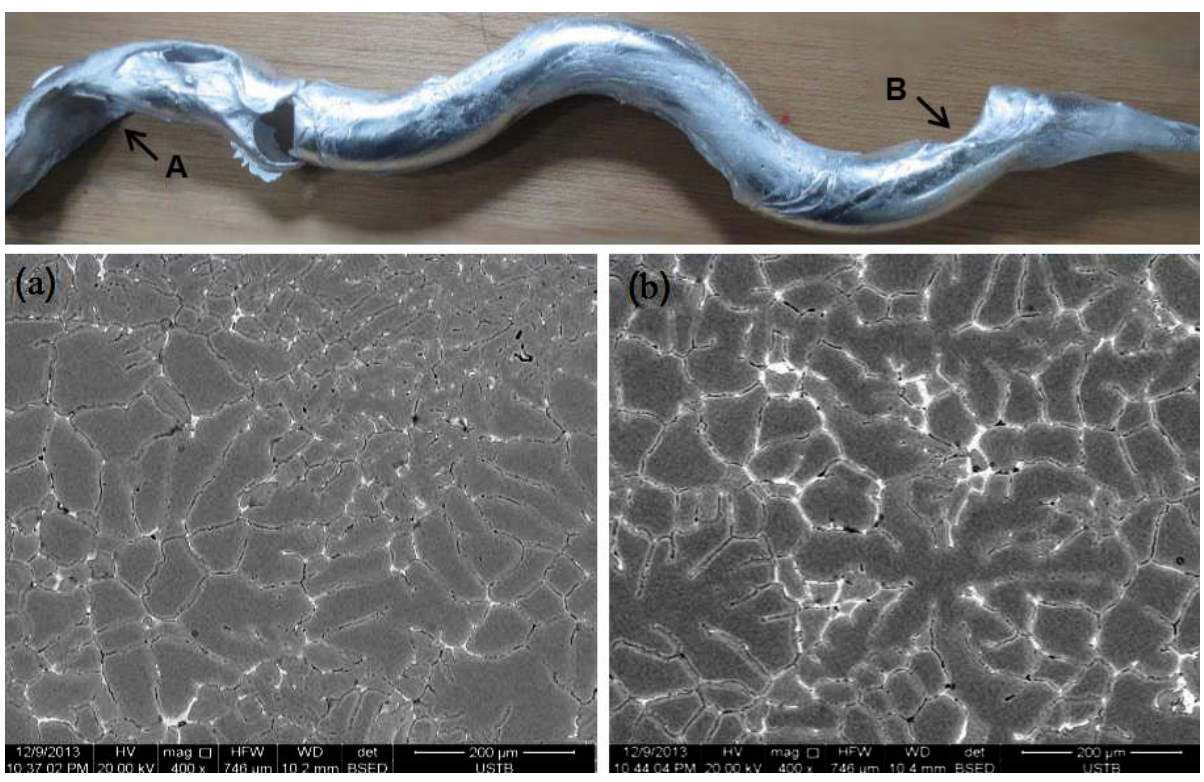

Fig. 12: Microstructures of solidified shell in marked places "A" (a) and "B" (b)

\section{Conclusions}

In this study, we have investigated the effects of processing parameters of WSPC and cooling conditions on the fabrication of Al-Zn-Mg-Cu alloy semisolid slurries. The following conclusions can be drawn:

(1) The morphology of primary $\alpha$-Al grains in Al-Zn-Mg-
$\mathrm{Cu}$ alloy melt converted from dendritic to rosette-like and nearspherical grains when prepared with WSPC. With the decrease of pouring temperature from $740{ }^{\circ} \mathrm{C}$ to $680{ }^{\circ} \mathrm{C}$, the average primary $\alpha$-Al grains size decreases continuously and the average shape factor increases. With a given pouring temperature and the cooling water flow rate, the average primary $\alpha$-Al grain size decreases and the shape factor increases with the increasing of 
the number of turns. With the increase of the cooling water flow rate from $0 \mathrm{~L} \cdot h^{-1}$ to $900 \mathrm{~L} \cdot h^{-1}$ during the WSPC, the average primary $\alpha$-Al grain size increases gradually and the average shape factor decreases.

(2) The optimal parameters for semisolid slurry preparation of Al-Zn-Mg-Cu alloy during WSPC process are pouring temperature between $680^{\circ} \mathrm{C}$ and $700{ }^{\circ} \mathrm{C}$, the number of turns of 4 , and the cooling water flow rate of $450 \mathrm{~L} \cdot \mathrm{h}^{-1}$.

(3) During the preparation of semisolid Al-Zn-Mg-Cu slurry, the alloy melt changes the flow direction many times when flowing in a curved and closed serpentine channel, with the effect of "stirring" in the serpentine turn, and the primary nuclei gradually evolve into spherical and near-spherical grains.

\section{References}

[1] Spencer D B, Mehrabian R, Flemings M C. Rheological behavior of $\mathrm{Sn}-15 \mathrm{~Pb}$ in the crystallization range. Metallurgical Transactions, 1972, 3(7): 1925 $\square 1932$.

[2] Mao Weimin. Semisolid metal forming technology. Beijing: China Machine Press, 2004: 6-10. (In Chinese)

[3] Haghayeghi R, Zoqui E J, Halvaee A, et al. An investigation on semisolid Al-7Si-0.3Mg alloy produced by mechanical stirring, Journal of Materials Processing Technology, 2005, 169(3):

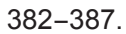

[4] Flemings M C. Behavior of metal alloys in the semisolid state. Metallurgical Transactions B, 1991: 22(3): 269 293.

[5] Chen Xingrun, Zhang Zhifeng, Xu Jun. Effects of annular

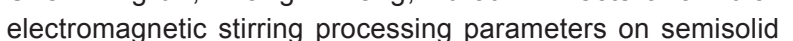

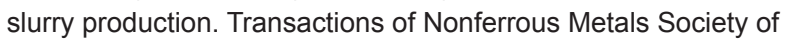
China, 2010, 20(3): 873 877.

[6] Fan Z. Semisolid metal processing. International Materials Reviews, 2002, 47(2): 4985.

[7] Shulin Lü, Shusen Wu, Chong Lin, et al. Preparation and rheocasting of semisolid slurry of $5083 \mathrm{Al}$ alloy with indirect ultrasonic vibration process. Materials Science and Engineering A, 2011, 528(29): $8635 \backsim 8640$.

[8] Bai Kun, Hu Rui, Li Jinshan, et al. Grain Refinement of NiCr-W Based Superalloy by Near Liquidus Casting. Rare Metal Materials and Engineering, 2014, 43(1): $1 \square \square$
[9] Xia K, Tausing G. Liquidus casting of a wrought aluminum alloy 2618 for thixoforming. Materials Science and Engineering: A, 1998, 246(1 2): 1 110.

[10] Guo Hongmin, Yang Xiangjie, Wang Jiaxuan, et al. Effects of

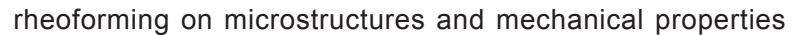
of 7075 wrought aluminum alloy. Transactions of Nonferrous Metals Society of China, 2014, 24(4): 954960.

[11] Liang Bo, Xu Jun, Zeng Yi Dan, et al. Study on the

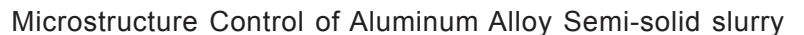
Prepared by MSMT Technology. Foundry Technology, 2008, 29(11):1518 1521.

[12] Guo Hongmin, Yang Xiangjie, Luo Xuequan, et al. Effects of Angular Oscillation on Semi-solid Microstructure of A356

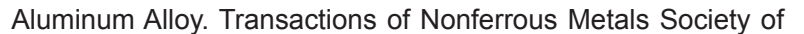
China, 2009, 19(12): 2106 2111.

[13] Toshio H, Shinsuke S. Casting of aluminum alloy ingots for thixoforming using a cooling slope. Journal of materials processing technology, 2001, 118(1-3): 169 172.

[14] Canyook R, Wanansin J, Wisuthmethangkul S, et al. Characterization of the microstructure evolution of a Semisolid metal slurry during the early stages. Acta Materialia, 2012, 60(8): 35013510.

[15] Chen Zhengzhou, Mao Weimin, Wu Zongchuang. Influence of प A356 aluminum alloy slurry. Transactions of Nonferrous Metals Society of China, 2011(5): 985 990.

[16] Chen Zhengzhou, Mao Weimin, Wu Zongchuang. Mechanical

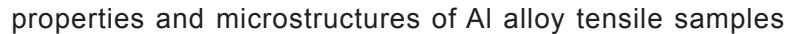
produced by serpentine channel pouring rheo-diecasting process. Transactions of Nonferrous Metals Society of China, 2011(7): $1473 \square 1479$.

[17] Zhang Xinmeng, Mao Weimin, Zhu Wenzhi. Influence of Zn and $\mathrm{Cu}$ Contents on Hot Cracking Behavior and Microstructure of 7075 Aluminum Alloys. Special Casting \& Nonferrous Alloys, 2014, 34(12): 1336 1339. (In Chinese)

[18] Zhu Wenzhi, Mao Weimin, Yang Bin. Preparation of semisolid 7075 aluminum alloy slurry by serpentine pouring channel. Special Casting \& Nonferrous Alloys, 2013, 33(2): 145 147. (In

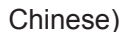

[19] Zhu Wenzhi, Mao Weimin, Tu Q. Preparation of semisolid 7075 aluminum alloy slurry by serpentine pouring channel. Transactions of Nonferrous Metals Society of China, 2014, 24(4): 954 960

This study was financially supported by the National Natural Science Foundation of China (Grant No. 51701078), China Postdoctoral Science Foundation (Grant Nos. 2018M632846 and 2018T110756) and the Scientific Research Program of Hubei Provincial Education Department (Grant No. B2016053). 